\title{
Vocabulário controlado e indexação social de imagens de arquitetura: um sistema de organização do conhecimento em ambiente colaborativo
}

\author{
Cibele Araújo Camargo Marques dos Santos \\ Universidade de São Paulo, Escola de Comunicações e Artes, São Paulo, SP, Brasil \\ cibeleac@usp.br \\ Vânia Mara Alves Lima \\ Universidade de São Paulo, Escola de Comunicações e Artes, São Paulo, SP, Brasil \\ vamal@usp.br
}

DOI: https://doi.org/10.26512/rici.v13.n1.2020.29566

Recebido/Recibido/Received: 2019-12-03

Aceitado/Aceptado/Accepted: 2020-02-10

Resumo: Este trabalho tem por objetivo relatar a pesquisa realizada para o desenvolvimento de um vocabulário controlado em ambiente colaborativo web, o qual permite a indexação social pelo tagueamento das imagens postadas tanto pelo usuário pessoal quanto pelo usuário institucional. Criado para preservação e divulgação de imagens de arquitetura brasileira, o Arquigrafia é também uma rede social formada por estudantes, professores, pesquisadores, profissionais e interessados em fotografias de Arquitetura e Espaços Urbanos. Assim, foi necessária a análise da lista de tags para melhoria da consistência da indexação, buscando-se uma organização conceitual dos termos do domínio a partir da aplicação de metodologia terminológica, visando ainda o alinhamento dos termos do vocabulário em construção com outros sistemas de organização do conhecimento.

Palavras-chave: ambiente colaborativo. imagens de arquitetura. indexação social. vocabulário controlado. sistemas de organização do conhecimento.

Controlled vocabulary and social indexing of architectural images: a knowledge organization system in a collaborative environment

Abstract: This paper aims to report the research carried out for the development of a controlled vocabulary in a collaborative web environment, which allows social indexing by tagging the images posted by both the personal user and the institutional user. Created for the preservation and dissemination of Brazilian architecture images, Arquigrafia is also a social network formed by students, teachers, researchers, professionals and others interested in architecture and urban spaces photography. Thus, it was necessary to analyze the list of tags to improve the consistency of indexing, seeking a conceptual organization of domain terms from the application of terminological methodology, aiming at the alignment of vocabulary terms under construction with other knowledge organization systems.

Keywords: collaborative environment. architectural images. social indexing. controlled vocabulary. knowledge organization systems.

\section{Vocabulario controlado e indexación social de imágenes arquitectónicas: un sistema de organización del conocimiento en un entorno web colaborativo}

Resumen: El objetivo de este trabajo es informar la investigación realizada para el desarrollo de un vocabulario controlado en un entorno web colaborativo, que permite la indexación social al etiquetar las imágenes publicadas tanto por el usuario personal como por el usuario institucional. Creado para la preservación y difusión de imágenes de la arquitectura brasileña, el Arquigrafia es también una red social formada por estudiantes, profesores, investigadores, profesionales y aquellos interesados en 
fotografías de Arquitectura y Espacios Urbanos. Por lo tanto, fue necesario analizar la lista de etiquetas para mejorar la consistencia de la indexación, buscando una organización conceptual de los términos del dominio a partir de la aplicación de la metodología terminológica, y también con el objetivo de alinear los términos del vocabulario en construcción con otros sistemas de organización del conocimiento.

Palabras claves: entorno web colaborativo. imágenes de arquitectura. indexación social. vocabulario controlado. sistemas de organización del conocimiento.

\section{Introdução}

Este trabalho objetiva relatar a pesquisa realizada no período de 2017-2019 na plataforma Arquigrafia, ambiente colaborativo na web, projeto interdisciplinar que envolve pesquisadores das áreas de Arquitetura, Ciência da Informação e Ciência da Computação.Desenvolvido desde 2009, para pesquisa, preservação e divulgação de imagens de arquitetura brasileira, conta com mais de 13200 fotografias e por suas características, se insere no que hoje se denomina de Humanidades Digitais.

O ARQUIGRAFIA se diferencia dos numerosos repositórios de imagens da web pela sua natureza colaborativa onde possibilita ao usuário, seja ele pessoal, ou institucional realizar uma indexação livre, mas ao mesmo tempo busca desenvolver um vocabulário controlado, a partir de uma lista de sugestão de termos selecionados por especialistas da área e das tags atribuídas pelos usuários pessoais à sua coleção de imagens. Esse vocabulário controlado tem por objetivo dar a garantia terminológica à indexação institucional, e ao mesmo tempo, deve ser flexível para incorporar termos novos coletados a partir da indexação social.

Assim, visando a consistência da indexação social, a lista de tags, resultado dessa indexação, é extraída do sistema e a partir da aplicação de metodologia terminológica, essas tags são incluídas no sistema conceitual do domínio, ou seja, são incorporadas ao vocabulário controlado da plataforma o qual deverá ter seus descritores alinhados a outros sistemas de organização do conhecimento. Como resultado busca-se implementar no ARQUIGRAFIA uma ferramenta para representação e recuperação da informação, alinhada com outros sistemas de organização do conhecimento que são referência no domínio, como o Art and Architectural Thesaurus do Getty Research Institute.

\section{A plataforma ARQUIGRAFIA}

O ARQUIGRAFIA é um ambiente web colaborativo dedicado à pesquisa, preservação e divulgação de imagens de arquitetura brasileira constituído por ferramentas web baseadas na arquitetura de participação, onde o usuário é protagonista do compartilhamento de textos, áudios, vídeos e neste caso específico de imagens, sendo que esse ambiente digital promove interações colaborativas atuando como uma rede social. 
Com um site responsivo desde a atualização da interface implementada em 2019, o acesso ao sistema, via smartphone, permite estimular os usuários a navegar e postar em acervo digital de fotografias georeferenciadas enquanto circulam pelas cidades, visualizam as imagens, interagem e colaboram entre si (ROZESTRATEN; PEREIRA, 2014). O site traz uma landing page (Figura 1) desenvolvida para informar sobre o ambiente e os recursos básicos disponíveis no sistema.

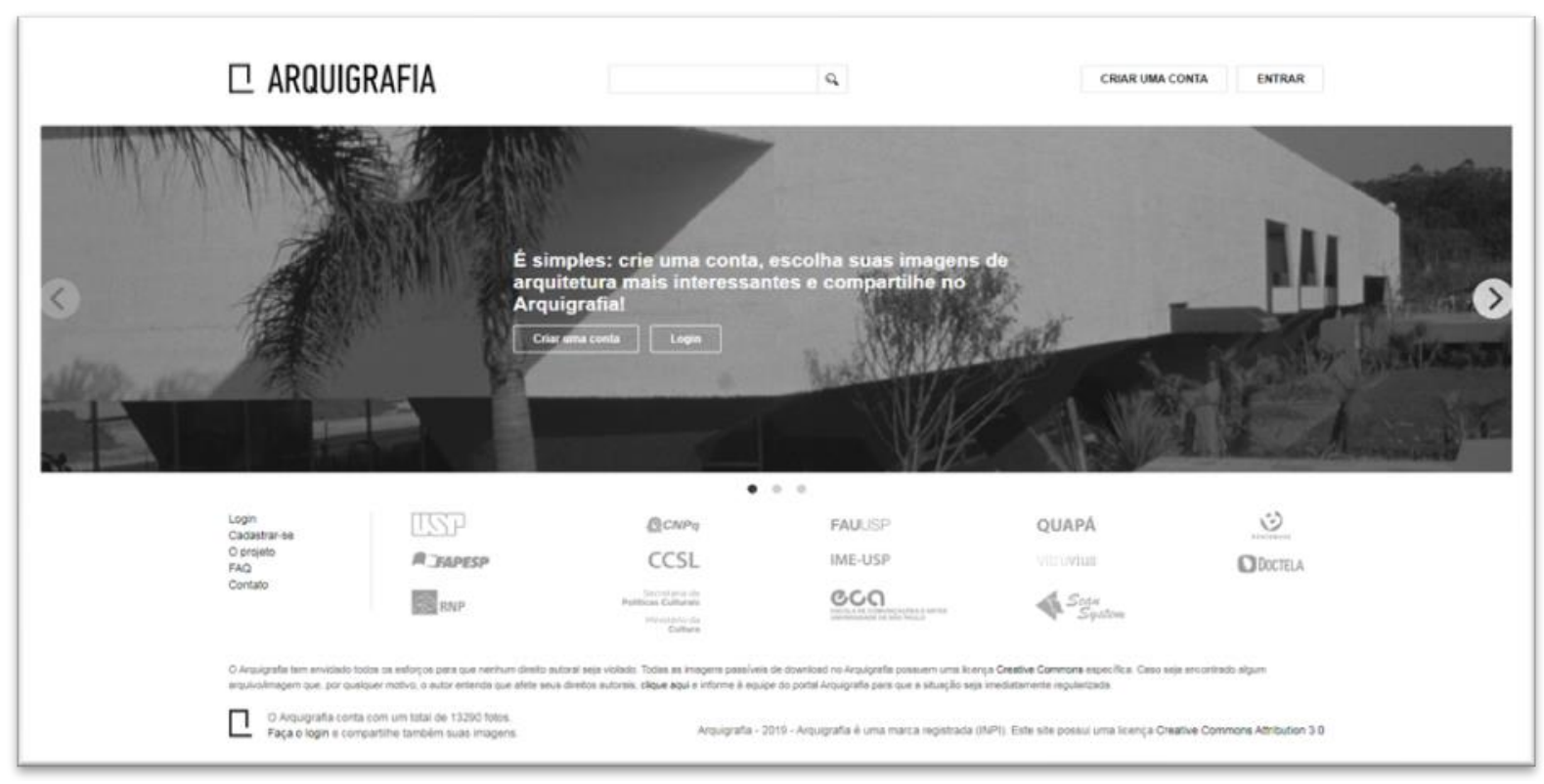

Figura 1 - ARQUIGRAFIA

Fonte: http://www.arquigrafia.org.br

Este ambiente digital contribui com a pesquisa sobre o patrimônio arquitetônico e urbanístico, além de permitir a organização de imagens de arquitetura brasileira na web (LIMA et al., 2016). O projeto apresenta-se como uma iniciativa diferenciada, um repositório de imagens para preservação e difusão, e segundo Rozestraten, Lima e Santos (2017), esse repositório digital é modelado, implementado e gerenciado por uma equipe interdisciplinar, sendo um laboratório para criação e aplicações de ferramentas web 2.0 e suscita interesse tanto no Brasil como no exterior, com vários trabalhos publicados.

Promove interações colaborativas entre pessoas e instituições a partir das fotos compartilhadas (Figura 2) e descritas através da inserção de informações em campos obrigatórios, campos complementares, sendo a gestão de direitos autorais realizada pelo uso de licença Criative Commons e autorizações fornecidas pelos autores ou detentores dos direitos das fotos. 


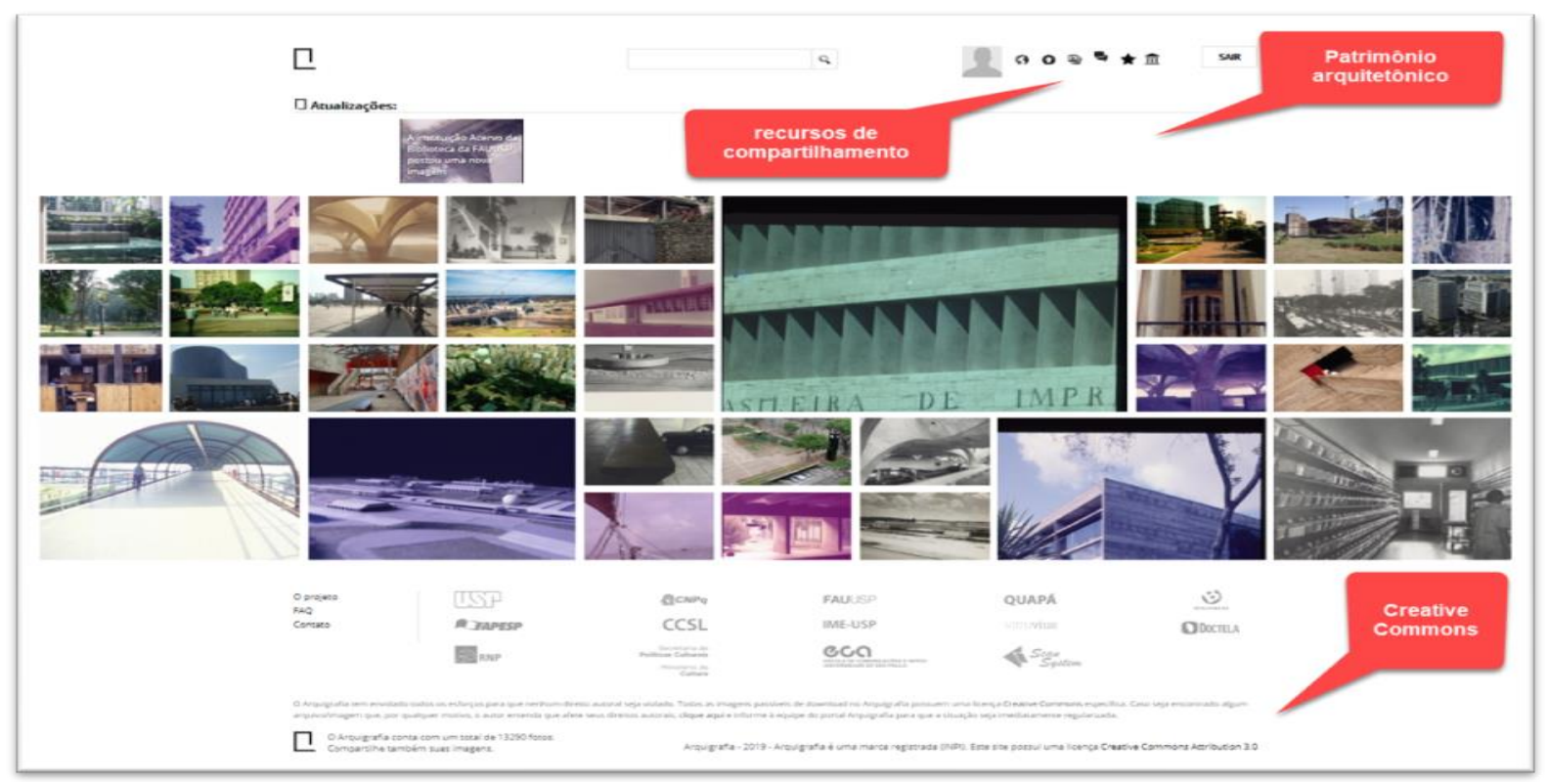

Figura 2 - ARQUIGRAFIA - acesso do usuário

Fonte: https://www.arquigrafia.org.br/home

No perfil do usuário existe a possibilidade de chat para interação com outros usuários como rede social, criação de álbuns de fotos, interpretação de imagens, e recursos de compartilhamento e gamificação para revisões de consistência de informações nos registros de imagens na opção relativa a contribuições disponíveis para o usuário.

Tanto os usuários com acesso pessoal como os usuários com acesso institucional podem inserir fotos de arquitetura de coleções próprias ou acervos específicos. Para fazer o upload de uma foto, é necessário preencher pelo menos título e autor da imagem, país e tags, que são etiquetas ou marcadores, que representam a indexação de assunto da imagem postada (ROZESTRATEN; LIMA; SANTOS, 2017).

A inserção das tags ou etiquetas de assunto no ARQUIGRAFIA ocorre pelo tagueamento das fotografias postadas pelo usuário pessoal e de certa forma também pelo usuário institucional no cadastro das imagens do acervo da Biblioteca da FAU/USP, acervo Quapá ou do Museu Republicano Convenção de Itu, que embora atenda a procedimentos especificados na política de indexação do ambiente, permite a adição de termos novos em linguagem natural. Dessa forma, apresenta-se uma tensão entre a indexação livre e o controle de vocabulário realizado ao mesmo tempo, através de lista de sugestão de termos para indexação que foi preparada por especialistas das áreas de Arquitetura e Biblioteconomia.

\section{A indexação social}

A inclusão de tags ou marcadores pelos usuários com linguagem natural é denominada folksonomia, indexação social ou tagueamento social. Angus et al. (2010) e Bradley (2011) 
estudaram um site de compartilhamento e rede social de fotos, o Flickr o qual também utiliza a folksonomia para assuntos e concluíram que este processo de indexação pode contribuir para a criação e gestão de acervos digitais, pois realizado de forma colaborativa, permite distribuir os recursos, atividades, e diminuir os custos de forma que se torna importante para a organização, recuperação e o acesso à informação digital.

O estudo de Angus et al. (2010) investigou de forma exploratória potencial uso do site de imagens Flickr, como um recurso de imagem acadêmica identificando imagens marcadas com tags pertencentes a categorias matérias acadêmicas. A análise de conteúdo de imagem e a análise de frequência de termo forneceram informações do contexto da imagem. Os resultados deste estudo mostraram a possibilidade de uso da ferramenta como recurso para imagens específicas em algumas áreas do conhecimento e para estudos acadêmicos individuais. Esse resultado pode reforçar a pertinência da utilização de indexação social de um repositório de imagens desenvolvido para fins acadêmicos, de pesquisa e extensão como o ARQUIGRAFIA.

Para Font, Serra e Serra (2013), a marcação colaborativa surgiu como uma solução para rotular e organizar conteúdo digital na web, mas estes sistemas de marcação colaborativa e indexação social apresentam problemas quanto à ambiguidade das tags, quanto aos sinônimos e à quantidade de palavras utilizadas, sendo possível inferir que a organização e navegação de conteúdo marcado dessa forma podem apresentar dificuldades para a recuperação eficiente da informação.

Para Moreiro Gonzalez (2011), a folksonomia permite o emprego livre de etiquetas semânticas, é um sistema explicito e relevante para os interesses de um site, que se afasta da indexação realizada de cima para baixo, trazendo o benefício do vocabulário pessoal e da contribuição social para recuperação e controle de assuntos, podendo ocorrer retroalimentação entre a indexação social e o vocabulário controlado. $\mathrm{O}$ autor reforça que as folksonomias permitem estudar os termos mais utilizados no sistema, e podem evoluir conforme as tendências da área e segundo as comunidades que empregam os termos.

Vander Wal, criador do termo folksonomia, identificou dois tipos de folksonomia: a folksonomia genérica onde usuários diferentes etiquetam o mesmo objeto com suas próprias tags, e a folksonomia específica onde uma ou poucas pessoas inserem as etiquetas (MOREIRO GONZALEZ, 2011; RAFFERTY, 2018).

O etiquetamento realizado no ARQUIGRAFIA relaciona-se ao modelo de folksonomia específica. Assim, encontramos neste ambiente colaborativo um sistema de organização do conhecimento misto, onde qualquer usuário pode fazer o upload de uma imagem e taguear (etiquetar) usando a lista de sugestões (vocabulário controlado) ou adicionando termos, mas 
só este usuário pode editar as informações e as tags que insere. Contudo, os outros usuários podem contribuir revisando as informações e indicando complementações e correções via sistema de contribuições para edição do próprio autor do registro.Ocorre que, apesar da facilidade de uso da indexação social e da aproximação com o vocabulário ativo dos usuários, a falta de controle na linguagem pode apresentar dificuldades para a recuperação da informação.

A norma ANSI/NISO Z39.19 denominada "Guidelines for the construction, format, and management of monolingual controlled vocabularies" define "Vocabulário Controlado" como uma lista de termos explicitados e controlados, sendo que estes termos não podem ter ambiguidade e devem apresentar definições que não sejam redundantes (NATIONAL INFORMATION STANDARDS ORGANIZATION, 2010). Assim, é possível entender a tensão existente em um sistema de informação como o ARQUIGRAFIA que representa imagens de acervos institucionais e imagens pessoais, e precisa atender às demandas da organização dessas imagens para fins de recuperação acadêmica e de preservação, e ao mesmo tempo, contar com a indexação social e a participação do usuário pessoal para a retroalimentação do sistema com imagens e marcadores.

Por esse motivo, ainda precisamos de um instrumento que possa dar a garantia terminológica para a representação e a recuperação da informação nos ambientes colaborativos.

\section{Os sistemas de organização do conhecimento}

A definição dos Sistemas de Organização do Conhecimento (SOC), segundo Hodge (2000) inclui todos os tipos de esquemas para organização da informação como os sistemas de classificação e categorização, listas de cabeçalhos de assunto, controle de autoridades, vocabulários estruturados, tesauros, taxonomias e esquemas emprestados de outras áreas como as redes semânticas e as ontologias. Ainda em relação aos SOC, a autora complementa que pode ser aplicado a registros em forma de metadados para cada recurso cadastrado, podendo ser incorporado em metatags ou separado dos recursos da biblioteca digital sempre com a finalidade exclusiva de organizar conteúdo para apoiar a recuperação de itens relevantes.

Ainda segundo a autora, os SOCs podem ser usados para fornecer acesso às bibliotecas digitais para comunidades diferentes com um assunto alternativo como recursos visuais ou geográficos, acesso multilíngue ou suporte à pesquisa de texto livre.

Embora a definição de SOC refira-se em um primeiro momento aos vocabulários controlados e estruturados, na "ISKO Encyclopedia of Knowledge Organization (IEKO)" editada 
por Hjørland e Gnoli (2019), a partir da literatura da área de Organização do Conhecimento, a folksonomia ou tagueamento é categorizada com um tipo de SOC. Portanto, estamos considerando que o processo de tagueamento realizado no ARQUIGRAFIA pode se inserir nos sistemas de organização do conhecimento, com a particularidade de permitir a indexação social e um controle relativo de termos como mostrado a seguir.

No momento da inserção das tags pelo usuário, o sistema sugere termos do Vocabulário Controlado USP que foram selecionados por especialistas em Arquitetura e bibliotecários com experiência na área, como termos pertinentes à indexação de imagens de Arquitetura e também de assuntos já inseridos pelos usuários, aceitando também a inclusão de novas tags pelo usuário (Figura 3).

O controle de vocabulário com a utilização de uma lista gerada a partir das tags dos usuários ou por uma linguagem documentária não se constitui no único recurso para a consistência da indexação, sendo necessário também o conhecimento das características do suporte e de seu conteúdo, regras claras sobre o processo de indexação, conhecimento da área temática e treinamento em indexação específico para o ambiente, principalmente para os usuários institucionais, embora a política de indexação prevista no Manual de Procedimentos Técnicos do projeto ARQUIGRAFIA, organizado por ROZESTRATEN et al. (2018), possa ser usada como boas práticas pelos usuários pessoais.

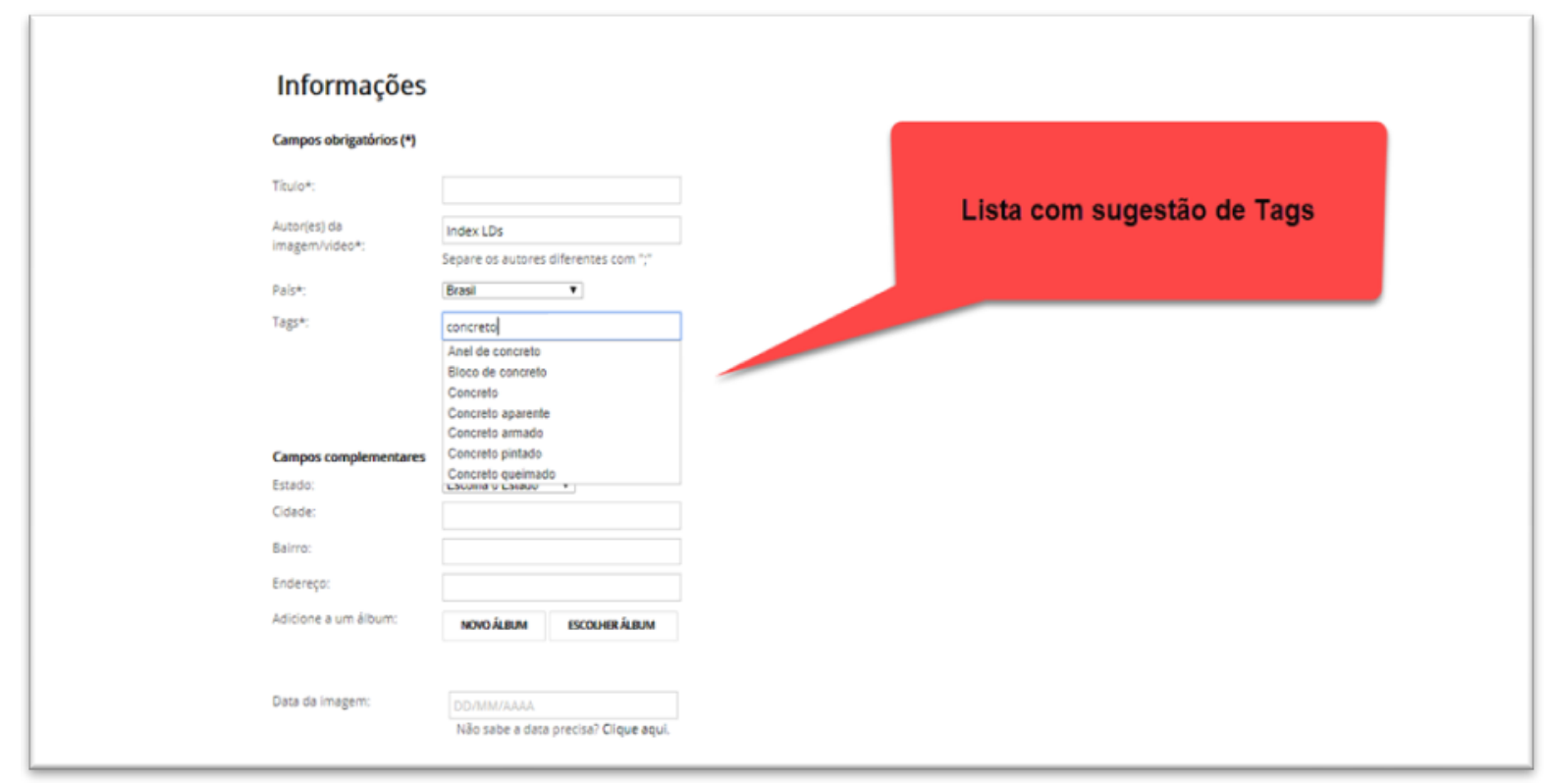

Figura 3- Lista de tags no ARQUIGRAFIA na inserção de dados de imagem Fonte:Extraído de https://www.arquigrafia.org.br/photos/upload

A política de indexação do projeto recomenda a indicação de tags para a representação temática dos materiais utilizados na construção da obra que estejam visíveis no 
primeiro plano da imagem, além da indicação dos elementos arquitetônicos presentes identificados a partir do tipo de edificação e/ou espaço urbano e suas funções.

\section{Metodologia}

A lista de tags atribuídas pelos usuários pessoais, na indexação de sua coleção de imagens foi utilizada como corpus para aprimoramento da lista de sugestão do ARQUIGRAFIA, que era constituída por 1145 termos (SANTOS; SANTOS, 2017). A análise dessa lista foi realizada durante 2017-2019 buscando-se a inclusão de seus termos, definições e, considerando ainda, as relações de equivalência e hierárquicas entre eles e os termos da lista original.

O procedimento metodológico para as definições dos termos do ARQUIGRAFIA é baseado no fazer terminológico descrito por Lima, Costa e Guimarães (2017) e considerado fundamental para o processo de elaboração e gestão de um vocabulário controlado, pois parte da terminologia da área de domínio referente, no caso a Arquitetura, permitindo a partir da compilação da definição do termo, sua categorização conceitual e estruturação hierárquica.

Assim a lista atual, constituída por 1300 termos foi organizada em 4 categorias representativas da Arquitetura: forma (tipo de edificação); técnica (técnica construtiva utilizada); materiais (materiais utilizados na construção) e função (uso da edificação, passado ou presente).

A lista foi compartilhada em planilha no Google Drive (Figura 4) com os alunos e professores do grupo de pesquisa contendo os itens: definição; fonte (dicionário ou tesauro de onde foi originada a definição); definição proposta (a partir de conceitos fundamentais e de acordo com o fazer terminológico); remissivas e sinônimos; se o termo constava do Vocabulário Controlado USP; hierarquia no Vocabulário USP; relações possíveis no vocabulário ARQUIGRAFIA; hierarquia sugerida e consistência. 


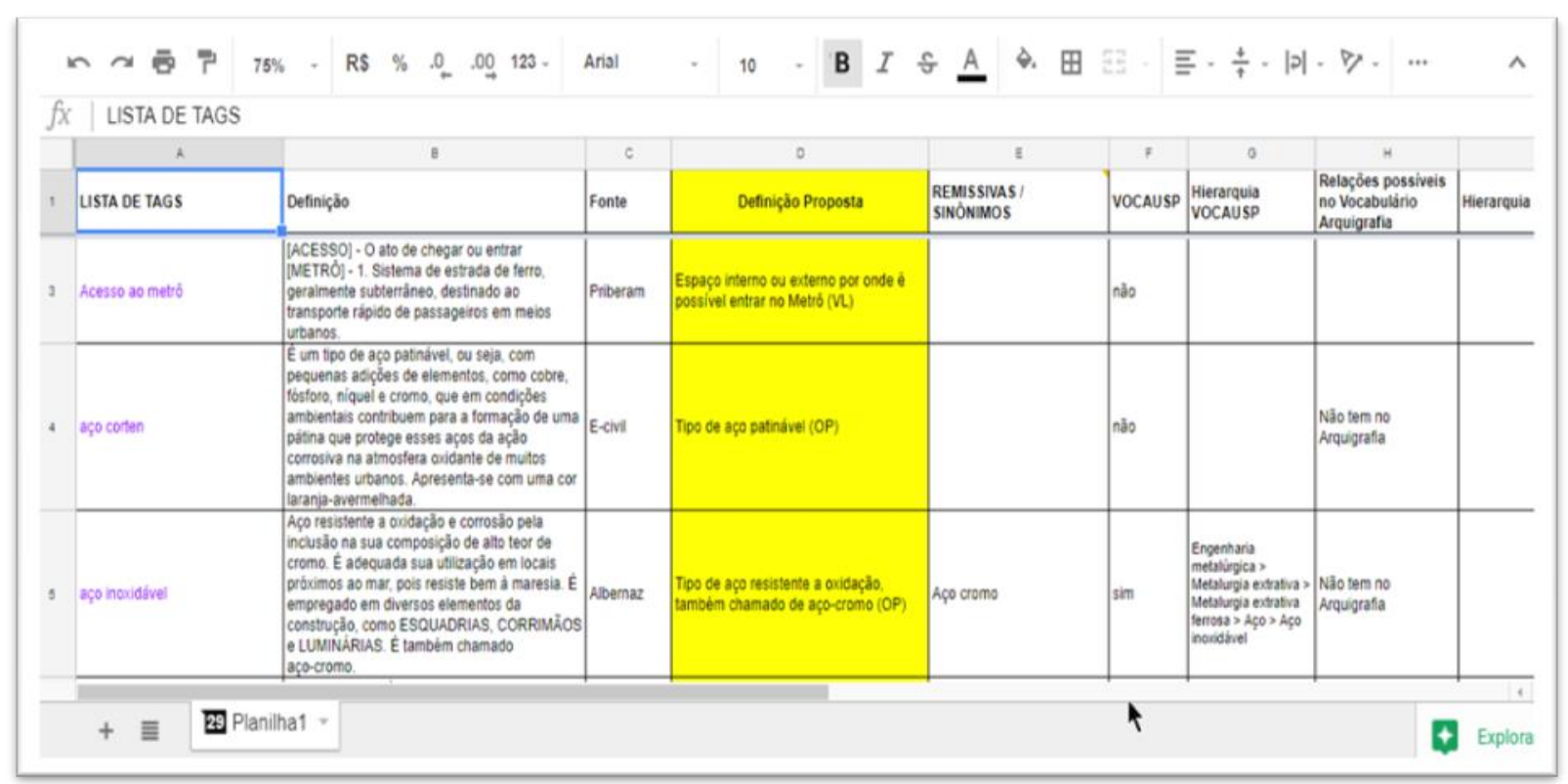

Figura 4 - Lista de Tags do ARQUIGRAFIA com termos para definição Fonte: Elaborado pelo grupo de pesquisa do ARQUIGRAFIA

Na sequência, a partir das definições dos termos foram identificadas as categorias temáticas e os termos categorizados foram inseridos em um software de mapa mental (Figura 5) que permitiu a visualização da hierarquia e posterior conversão do mapa em planilha de dados a ser inserida no ARQUIGRAFIA.

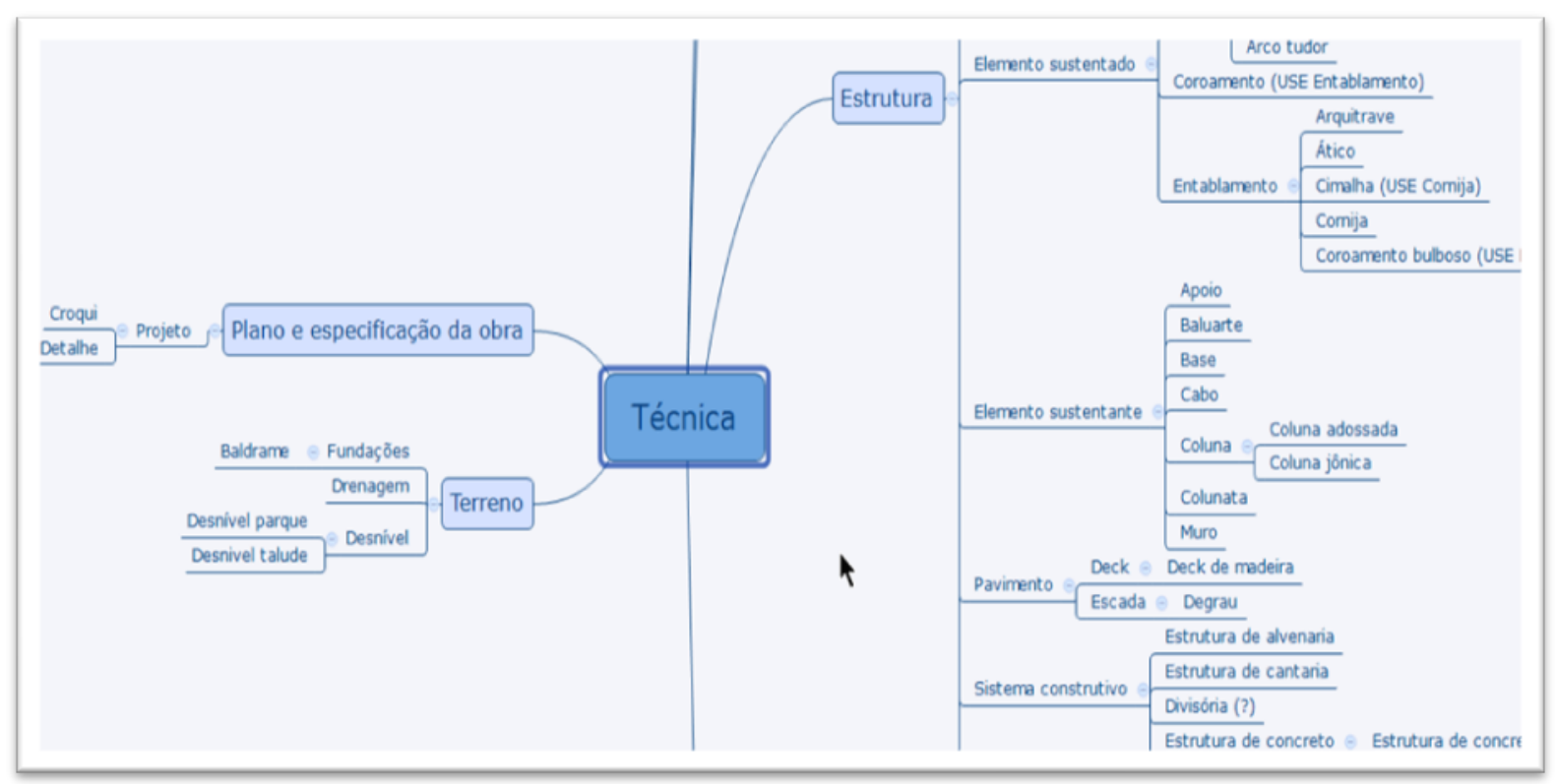

Figura 5 - Mapa mental dos termos por categorias Fonte: Elaborado pelo grupo de pesquisa do ARQUIGRAFIA 
A lista de definições e o mapa mental que contextualizam o vocabulário gerado a partir das tags do ARQUIGRAFIA apresentam potencial para o desenvolvimento de um vocabulário controlado para indexação de informações imagéticas, audiovisuais e textuais em Arquitetura.

\section{Conclusões}

No momento da inserção das tags o usuário deverá visualizar a lista de sugestões do ARQUIGRAFIA, já enriquecida pelas tags, podendo escolher um dos 1300 termos sugeridos, ou incluir uma nova tag. A indexação social é mantida, pois traz o benefício do vocabulário pessoal dos usuários e a contribuição destes para a recuperação da informação, permitindo a retroalimentação entre o tagueamento e o vocabulário controlado previsto para uso institucional, bem como estabelecendo uma relação entre usuário, imagem e a tag/termo utilizado.

Assim, os termos para indexação institucional ou social, são apresentados de forma mais consistente, possibilitando uma recuperação das imagens cadastradas por categoria: forma, material, função e técnica, mas também aprimorando a representação por assunto e formalizando a indexação social como fonte para um sistema de organização do conhecimento.

A inserção de tags pelos usuários nas imagens do ARQUIGRAFIA com o uso de uma lista de sugestão de termos criada a partir de vocabulário controlado permitiu a identificação de um sistema de organização do conhecimento com características mistas e específicas, com a distribuição dos recursos e atividades de atualização da linguagem documentária compartilhada com o usuário.

Estabelecidas as relações terminológicas entre os 1300 termos, torna-se possível incluir esse sistema de organização do conhecimento em um software específico para gestão de vocabulários controlados, permitindo um mapeamento dos termos do domínio e seu alinhamento com outros sistemas de organização do conhecimento referência na área como, por exemplo, o Art and Architectural Thesaurus do Getty Research Institute.

Para apoiar a implementação desse sistema de organização do conhecimento no ARQUIGRAFIA observou-se a necessidade de aprofundar as pesquisas para o desenvolvimento do software +GRAFIA que gerencia o ambiente colaborativo.

\section{Referências}

ANGUS, E.; STUART, D.; THELWALL, M. Flickr's potential as an academic image resource: an exploratory study. Journal of Librarianship and Information Science, v. 42, n. 4, p. 268-278, 2010. 
BRADLEY, P. From Flickr to Playbills -- How to Find the Right Images. CILIP UPDATE with gazette, United Kingdom, p. 23-23, Jul., 2011.

FONT, F.; SERRA, J.; SERRA, X. Folksonomy-based tag recommendation for collaborative tagging systems. International Journal on Semantic Web and Information Systems, v. 9, n. 2, p. 1-30, 2013.

HODGE, G. Systems of knowledge organization for digital libraries: beyond traditional authority files. Washington, DC: Digital Library Federation, 2000.

HUGHES, A. V.; RAFFERTY, P. Inter-indexer consistency in graphic materials indexing at the National Library of Wales. Journal of Documentation, v. 67, n. 1, p. 9-32, 2011.

LIMA, V. M. A.; ROZESTRATEN, A.S.; SANTOS, C. A. C. M; MARQUES, E. A; SAMPAIO, L. A. Arquigrafia: um repositório digital de imagens em ambiente colaborativo web. RBBD Revista Brasileira de Biblioteconomia e Documentação, v. 12, p. 103-107, 2016.

LIMA, V. M. A.; COSTA, I. G.; GUIMARÃES, M. O. A Organização do Conhecimento no domínio das Artes: o fazer terminológico na gestão do vocabulário controlado. In: Memória, tecnologia e cultura na organização do conhecimento. Recife: Editora UFPE, 2017.

MOREIRO GONZÁLEZ, J. A. Linguagens documentárias e vocabulários semânticos para a web: elementos conceituais. Salvador: EDUFBA, 2011. 128 p.

NATIONAL INFORMATION STANDARDS ORGANIZATION. Guidelines for the construction, format, and management of monolingual controlled vocabularies. Baltimore: NISO, 2010. 172 p. (ANSI/NISO Z39.19-2005 R2010).

RAFFERTY, P. “Tagging". Knowledge Organization, v. 45, n. 6, p. 500-516, 2018.

ROZESTRATEN, A. S.; ANDRADE, B. M.; FIGUEIREDO, F. G. Manual de procedimentos técnicos do projeto arquigrafia. São Paulo: FAUUSP, 2018. 56p.

ROZESTRATEN, A. S.; LIMA, V. M. A.; SANTOS, C. A. C. M. ARQUIGRAFIA: digital images in the collaborative environment on the Web. In: IFLA Satellite Meeting 2017: Digital Humanities, 2017, Berlin. Digital Humanities. Haia: IFLA, 2017.

ROZESTRATEN, A. S.; PEREIRA, D. A. O. Arquigrafia entre 2009 e 2014. FAUUSP, 2014.

SANTOS, L.; SANTOS, C. A. C. M. Arquigrafia: um projeto de indexação de fotografias no meio digital. In: SIMPÓSIO INTERNACIONAL DE INICIAÇÃO CIENTÍFICA E TECNOLÓGICA DA USP, 2017, 25., São Paulo. Anais... Publicações SIICUSP. São Paulo: Universidade de São Paulo, 2017. v. 25. 